\title{
Experimental Determination of Phase Equilibria in the Co-Cr-V Ternary System
}

\author{
C.C. Zhao, Y. Yu, X.J. Liu, and C.P. Wang
}

(Submitted June 29, 2011; in revised form March 11, 2012)

\begin{abstract}
The phase equilibria in the Co-Cr-V ternary system were investigated by means of optical microscopy, electron probe microanalysis and $x$-ray diffraction. Four isothermal sections of the $\mathrm{Co}-\mathrm{Cr}-\mathrm{V}$ ternary system at $800,1000,1100$ and $1200{ }^{\circ} \mathrm{C}$ were established. The experimental results show that: (1) no ternary compound was found in this system; (2) the $\sigma$ and (V, Cr) phases form the continuous solid solutions from the $\mathrm{Co}-\mathrm{Cr}$ side to $\mathrm{Co}-\mathrm{V}$ side in the isothermal sections at 800-1200 ${ }^{\circ} \mathrm{C}$.
\end{abstract}

Keywords $\mathrm{Co}-\mathrm{Cr}-\mathrm{V}$, microstructure, phase diagrams

\section{Introduction}

The Co-Cr base alloys have been widely used as commercial magnetic recording materials, ${ }^{[1-4]}$ and the $\mathrm{Co}-\mathrm{V}$ system is a potential candidate of ultra-high density recording media because of phase separation between the ferromagnetic hcp phase and non-magnetic hcp phase, ${ }^{[5]}$ which is similar to the Co-Cr system. Thus, the Co-Cr-V ternary alloys as promising magnetic recording materials, are of both technical importance and academic interest. The properties of alloy materials are affected by the microstructure and composition. In order to properly understand the relationship between magnetic properties and microstructure, accurate information on the phase equilibria in the $\mathrm{Co}-\mathrm{Cr}-\mathrm{V}$ ternary system is required. However, only an isothermal section at $1150{ }^{\circ} \mathrm{C}$ in the $\mathrm{Co}-\mathrm{Cr}-\mathrm{V}$ system reported by Kuznetsov et al. ${ }^{[6]}$ was available. Therefore, it is important to comprehensively determine the phase equilibria in the Co-Cr-V ternary system.

The $\mathrm{Co}-\mathrm{Cr}$ binary system has been studied by many researchers, ${ }^{[7-9]}$ the latest version experimentally investigated and thermodynamically calculated by Oikawa et al. ${ }^{[9]}$ shows five phases $\left((\alpha \mathrm{Co}),(\varepsilon \mathrm{Co}),(\mathrm{Cr}), \mathrm{L}\right.$, and $\left.\sigma-\mathrm{Cr}_{3} \mathrm{Co}_{2}\right)$, and a magnetically induced phase separation of the ferromagnetic $\left(\alpha_{\mathrm{f}} \mathrm{Co}\right)$ and the paramagnetic $\left(\alpha_{\mathrm{p}} \mathrm{Co}\right)$ in the range of $764-965{ }^{\circ} \mathrm{C}$. The melting point of the $\sigma-\mathrm{Cr}_{3} \mathrm{Co}_{2}$ phase is about $1280{ }^{\circ} \mathrm{C} .{ }^{[9]}$ Some researchers investigated the phase

C.C. Zhao, Y. Yu, X.J. Liu, and C.P. Wang, Department of Materials Science and Engineering, College of Materials, and Research Center of Materials Design and Applications, Xiamen University, Xiamen 361005, People's Republic of China. Contact e-mail: wangcp@xmu. edu.cn.

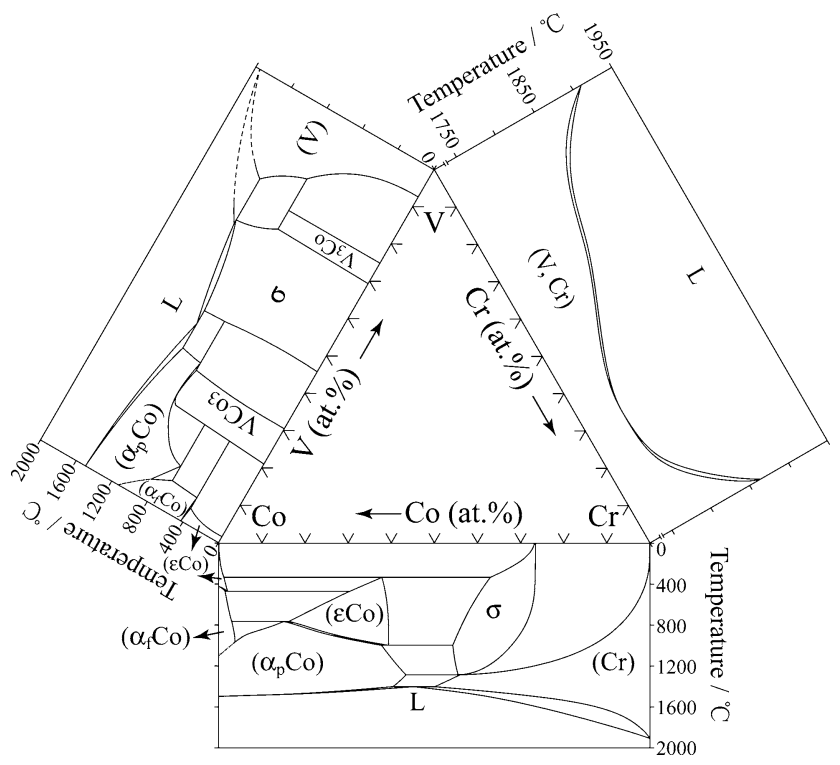

Fig. 1 Binary phase diagrams constituting the $\mathrm{Co}-\mathrm{Cr}-\mathrm{V}$ ternary system $^{[5,9,13]}$

Table 1 Stable solid phases in the three binary systems

\begin{tabular}{llcccc}
\hline System & Phase & $\begin{array}{c}\text { Pearson's } \\
\text { symbol }\end{array}$ & Prototype & Strukturbericht & Reference \\
\hline Co-Cr & $(\alpha \mathrm{Co})$ & $c F 4$ & $\mathrm{Cu}$ & $A 1$ & {$[9]$} \\
& $(\varepsilon \mathrm{Co})$ & $h P 2$ & $\mathrm{Mg}$ & $A 3$ & {$[9]$} \\
& $(\mathrm{Cr})$ & $c I 2$ & $\mathrm{~W}$ & $A 2$ & {$[9]$} \\
& $\sigma$ & $t P 30$ & $\sigma \mathrm{CrFe}$ & $D 8_{\mathrm{b}}$ & {$[9]$} \\
$\mathrm{Co}-\mathrm{V}$ & $(\alpha \mathrm{Co})$ & $c F 4$ & $\mathrm{Cu}$ & $A 1$ & {$[5]$} \\
& $(\varepsilon \mathrm{Co})$ & $h P 2$ & $\mathrm{Mg}$ & $A 3$ & {$[5]$} \\
& $\mathrm{VCo}_{3}$ & $h P 24$ & $\mathrm{VCo}_{3}$ & $\ldots$ & {$[5]$} \\
& $\sigma$ & $t P 30$ & $\sigma \mathrm{CrFe}$ & $D 8_{\mathrm{b}}$ & {$[5]$} \\
& $\mathrm{V}_{3} \mathrm{Co}$ & $c P 8$ & $\mathrm{SiCr}_{3}$ & $A 15$ & {$[5]$} \\
& $(\mathrm{V})$ & $c I 2$ & $\mathrm{~W}$ & $A 2$ & {$[5]$} \\
$\mathrm{Cr}-\mathrm{V}$ & $(\mathrm{V}, \mathrm{Cr})$ & $c I 2$ & $\mathrm{~W}$ & $A 2$ & {$[13]$} \\
\hline
\end{tabular}



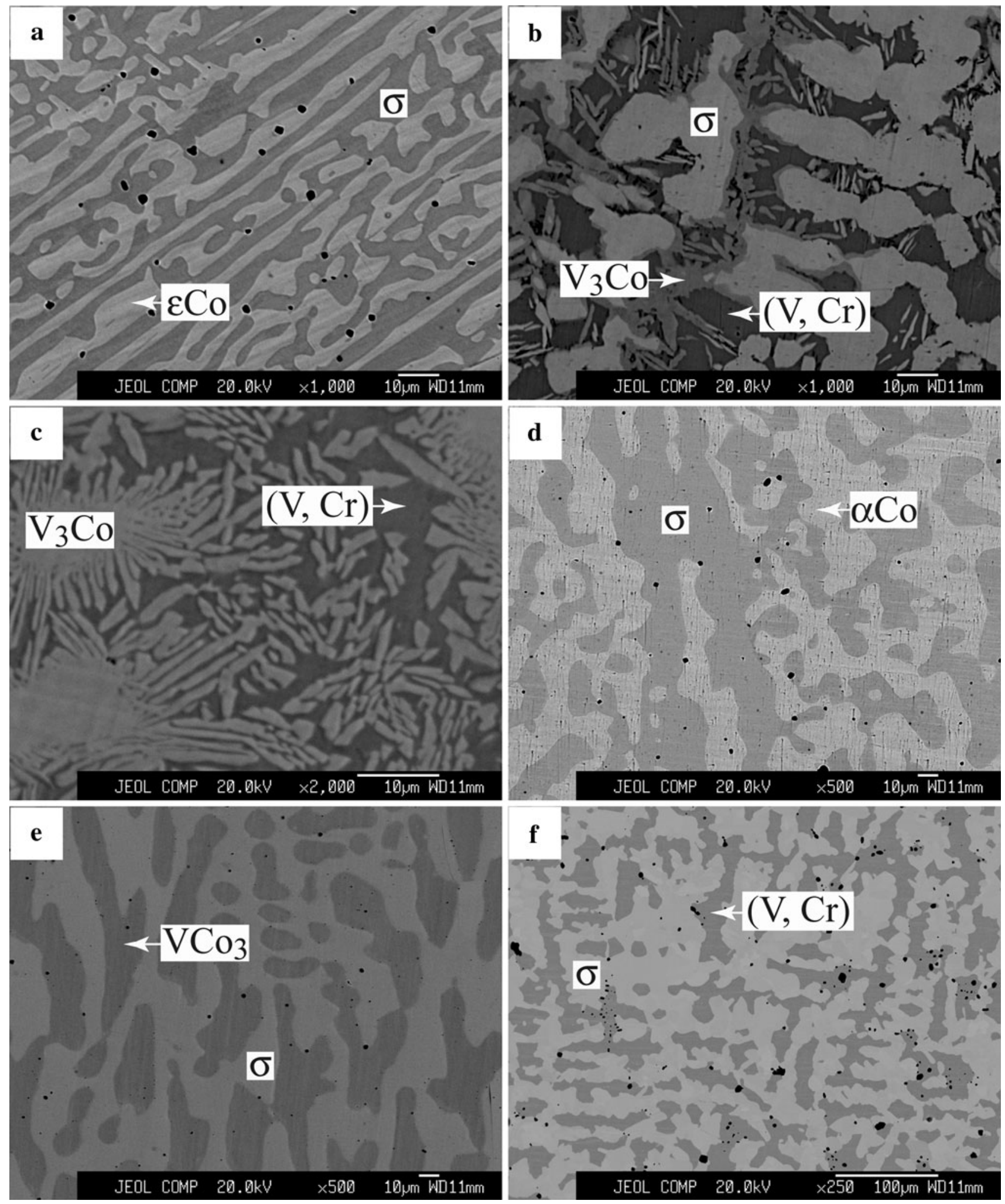

Fig. 2 BSE images of typical Co-Cr-V ternary alloys: (a) Co56:Cr40:V4 (at.\%) alloy annealed at $800{ }^{\circ} \mathrm{C}$ for 90 days; (b) Co24:Cr12:V64 (at.\%) alloy annealed at $800{ }^{\circ} \mathrm{C}$ for 90 days; (c) Co20:Cr4:V76 (at.\%) alloy annealed at $800{ }^{\circ} \mathrm{C}$ for 90 days; (d) Co56:Cr40:V4 (at.\%) alloy annealed at $1000{ }^{\circ} \mathrm{C}$ for 60 days; (e) Co64:Cr5:V31 (at.\%) alloy annealed at $1000{ }^{\circ} \mathrm{C}$ for 60 days and (f) Co29:Cr67:V4 (at.\%) alloy annealed at $1100{ }^{\circ} \mathrm{C}$ for 45 days 

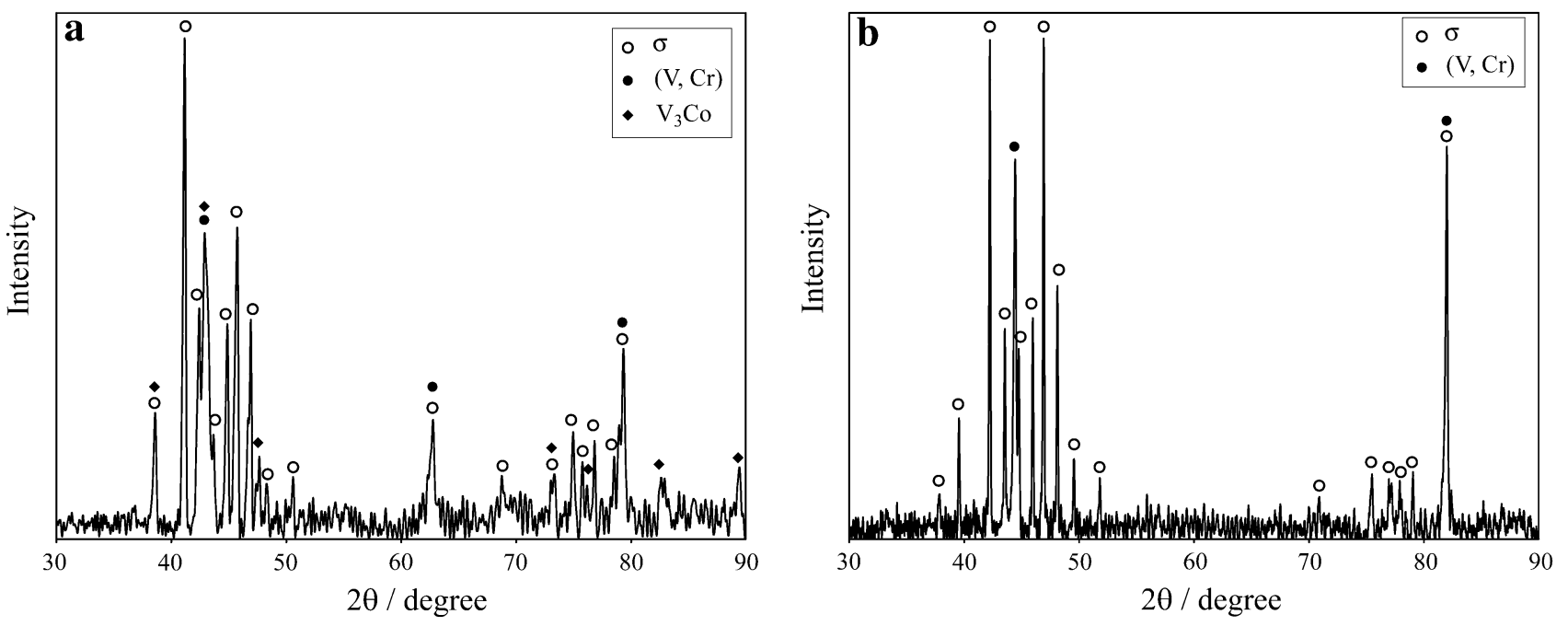

Fig. 3 XRD patterns obtained from (a) Co24:Cr12:V64 (at.\%) alloy annealed at $800{ }^{\circ} \mathrm{C}$ for 90 days and (b) Co29:Cr67:V4 (at.\%) alloy annealed at $1100{ }^{\circ} \mathrm{C}$ for 45 days

diagram of the Co-V system, ${ }^{[5,10-12]}$ but the Co-V diagram assessed by Okamoto ${ }^{[5]}$ in 2006 was more consistent with the experimental data of the present work. In the $\mathrm{Co}-\mathrm{V}$ binary system, there are three intermetallic phases $\left(\mathrm{VCo}_{3}\right.$, $\sigma-\mathrm{V}_{3} \mathrm{Co}_{2}$, and $\left.\mathrm{V}_{3} \mathrm{Co}\right)$ and a magnetically induced $(\alpha \mathrm{Co})$ phase separation of the ferromagnetic $\left(\alpha_{\mathrm{f}} \mathrm{Co}\right)$ and the paramagnetic $\left(\alpha_{\mathrm{p}} \mathrm{Co}\right)$ from 691 to $873{ }^{\circ} \mathrm{C}$. The transformation temperature from the $(\alpha \mathrm{Co})$ to $\mathrm{VCo}_{3}$ is reported to be $1045{ }^{\circ} \mathrm{C} .{ }^{[5]}$ The $\mathrm{Cr}-\mathrm{V}$ binary system is a simple system without any intermediate phase. ${ }^{[13]}$ The three sub-binary systems, Co-Cr, Co-V and $\mathrm{Cr}-\mathrm{V}$, are shown in Fig. 1. The stable solid phases in the three binary systems are summarized in Table 1.

The objective of the present work is to experimentally investigate the phase equilibria in the $\mathrm{Co}-\mathrm{Cr}-\mathrm{V}$ ternary system using optical microscopy $(\mathrm{OM})$, electron probe microanalysis (EPMA) and $\mathrm{x}$-ray diffraction (XRD). The experimental results are expected to help in understanding the microstructures of promising Co-Cr-V alloys and provide key support for the thermodynamic assessment of this system and the design of related material.

\section{Experimental Procedure}

Cobalt (99.9 wt.\%), chromium (99.7 wt.\%) and vanadium (99.7 wt.\%) were used as starting materials. Bulk buttons were prepared from pure elements by arc melting under high purity argon atmosphere using a non-consumable tungsten electrode. The ingots were melted 6 times in order to achieve homogeneity. The sample weight was around $20 \mathrm{~g}$ and the weight loss during melting was generally less than $0.20 \%$. Afterwards, the ingots were cut into small pieces for heat treatment and further observations. Plate-shaped specimens were put into quartz ampoules evacuated and backfilled with argon gas, then annealed in the temperature range from 800 to $1200{ }^{\circ} \mathrm{C}$. The samples were annealed at 800, 1000, 1100 and $1200{ }^{\circ} \mathrm{C}$ for $90,60,45$ and 20 days, respectively. At the end of the heat treatment, the specimens were quenched into iced water.

After standard metallographic preparation, microstructural observation of specimens was carried out by OM. The compositions (assumed to be equilibrium) of each phase in the annealed alloys were determined by EPMA (JXA-8100R, JEOL, Japan). Pure elements were used as standards, and the measurements were carried out at $20 \mathrm{kV}$. Every phase was analyzed seven times in different regions, and its composition was averaged. The XRD was used to identify the crystal structure of the constituent phase. The XRD measurements were carried out on a Phillips Panalytical X-pert diffractometer using $\mathrm{Cu}-\mathrm{K}_{\alpha}$ radiation at $40 \mathrm{kV}$ and $30 \mathrm{~mA}$. The data were collected in the range of $2 \theta$ from $20^{\circ}$ to $90^{\circ}$ at a step width of $0.0167^{\circ}$.

\section{Results and Discussion}

\subsection{Microstructural Morphologies}

Back-scattered electron (BSE) images of the typical ternary $\mathrm{Co}-\mathrm{Cr}-\mathrm{V}$ alloys are presented in Fig. 2. Phase identification was based on the composition as measured by EPMA and the XRD results. The two-phase equilibrium $\sigma+(\varepsilon \mathrm{Co})$ was identified in the Co56:Cr40:V4 (at.\%) alloy annealed at $800{ }^{\circ} \mathrm{C}$ for 90 days, and is shown in Fig. 2(a), where the $\sigma$ phase is dark gray and the $(\varepsilon \mathrm{Co})$ phase is light gray. In the Co24:Cr12:V64 (at.\%) alloy annealed at $800^{\circ} \mathrm{C}$ for 90 days, the three-phase microstructure $\mathrm{VCo}_{3}+\sigma+(\mathrm{V}$, Cr) was observed (Fig. 2b) and substantiated by the XRD results in Fig. 3(a). The finer needles in the dark (V, Cr) 
Table 2 Analyzed compositions of the annealed alloys

\begin{tabular}{|c|c|c|c|c|c|c|c|c|c|}
\hline \multirow[b]{3}{*}{ Temp., ${ }^{\circ} \mathrm{C}$} & \multirow[b]{3}{*}{ Alloys, at.\% } & \multirow{3}{*}{$\begin{array}{c}\text { Overall composition, } \\
\text { at.\% }\end{array}$} & \multirow{3}{*}{$\begin{array}{l}\text { Phase equilibria } \\
\text { Phase } 1 / \text { phase } \\
2 \text { /phase } 3\end{array}$} & \multicolumn{6}{|c|}{ Composition (at.\%) and the standard error } \\
\hline & & & & \multicolumn{2}{|c|}{ Phase 1} & \multicolumn{2}{|c|}{ Phase 2} & \multicolumn{2}{|c|}{ Phase 3} \\
\hline & & & & $\mathrm{Cr}$ & $\mathbf{V}$ & $\mathbf{C r}$ & $\mathbf{V}$ & $\mathrm{Cr}$ & $\mathbf{V}$ \\
\hline \multirow[t]{18}{*}{800} & Co92:Cr4:V4 & Co91.7:Cr4.1:V4.2 & $\alpha \mathrm{Co}$ & $4.1 \pm 0.02$ & $4.2 \pm 0.15$ & & & & \\
\hline & $\mathrm{Co} 79: \mathrm{Cr} 4: \mathrm{V} 17$ & Co78.8:Cr4.2:V17.0 & $\alpha \mathrm{Co} / \mathrm{VCo}_{3}$ & $5.0 \pm 0.16$ & $12.9 \pm 0.40$ & $4.6 \pm 0.15$ & $17.4 \pm 0.45$ & & \\
\hline & Co76:Cr16:V8 & Co75.6:Cr16.3:V8.1 & $\varepsilon \mathrm{Co}$ & $16.3 \pm 0.07$ & $8.1 \pm 0.10$ & & & & \\
\hline & Co70:Cr20:V10 & Co70.6:Cr19.9:V9.5 & $\varepsilon$ Co & $19.9 \pm 0.15$ & $9.5 \pm 0.09$ & & & & \\
\hline & Co70:Cr17:V13 & Co69.5:Cr17.2:V13.3 & $\varepsilon \mathrm{Co} / \mathrm{VCo}_{3}$ & $18.6 \pm 0.27$ & $12.4 \pm 0.34$ & $14.8 \pm 0.53$ & $15.2 \pm 0.07$ & & \\
\hline & Co60:Cr4:V36 & Co60.1:Cr4.2:V35.7 & $\mathrm{VCo}_{3} / \sigma$ & $1.7 \pm 0.12$ & $27.7 \pm 0.14$ & $5.9 \pm 0.12$ & $39.9 \pm 0.32$ & & \\
\hline & Co60:Cr12:V28 & Co59.8:Cr12.0:V28.2 & $\mathrm{VCo}_{3} / \sigma$ & $6.7 \pm 0.23$ & $25.2 \pm 0.56$ & $18.3 \pm 0.08$ & $30.6 \pm 0.24$ & & \\
\hline & Co60:Cr20:V20 & Co59.4:Cr20.6:V20.0 & $\mathrm{VCo}_{3} / \sigma$ & $8.8 \pm 0.13$ & $21.4 \pm 0.08$ & $29.7 \pm 0.85$ & $19.2 \pm 0.05$ & & \\
\hline & Co60:Cr32:V8 & Co59.6:Cr32.1:V8.3 & $\varepsilon \mathrm{Co} / \sigma$ & $26.6 \pm 0.60$ & $7.4 \pm 0.37$ & $42.1 \pm 0.23$ & $9.5 \pm 0.05$ & & \\
\hline & Co56:Cr40:V4 & Co55.8:Cr40.1:V4.1 & $\varepsilon \mathrm{Co} / \sigma$ & $31.4 \pm 0.04$ & $3.4 \pm 0.02$ & $48.9 \pm 0.47$ & $4.3 \pm 0.22$ & & \\
\hline & Co27:Cr8:V65 & Co27.4:Cr8.2:V64.4 & $\sigma / \mathrm{V}_{3} \mathrm{Co}$ & $7.5 \pm 0.19$ & $62.0 \pm 0.21$ & $10.4 \pm 0.43$ & $65.3 \pm 0.70$ & & \\
\hline & Co24:Cr12:V64 & Co23.8:Cr12.3:V63.9 & $\sigma / \mathrm{V}_{3} \mathrm{Co} /(\mathrm{V}, \mathrm{Cr})$ & $9.9 \pm 0.12$ & $60.0 \pm 0.17$ & $11.8 \pm 0.56$ & $64.1 \pm 0.07$ & $15.4 \pm 0.15$ & $65.9 \pm 0.30$ \\
\hline & Co26:Cr32:V42 & Co26.6:Cr31.3:V42.1 & $\sigma /(\mathrm{V}, \mathrm{Cr})$ & $26.6 \pm 0.15$ & $41.9 \pm 0.24$ & $39.3 \pm 0.13$ & $42.9 \pm 0.34$ & & \\
\hline & Co20:Cr60:V20 & Co21.4:Cr58.1:V20.5 & $\sigma /(\mathrm{V}, \mathrm{Cr})$ & $44.1 \pm 0.82$ & $22.6 \pm 0.57$ & $66.7 \pm 0.06$ & $19.5 \pm 0.03$ & & \\
\hline & Co20:Cr20:V60 & Co19.8:Cr19.8:V60.4 & $\sigma /(\mathrm{V}, \mathrm{Cr})$ & $13.2 \pm 0.27$ & $56.5 \pm 0.28$ & $23.3 \pm 0.14$ & $60.7 \pm 0.11$ & & \\
\hline & Co20:Cr76:V4 & Co20.8:Cr75.1:V4.2 & $\sigma /(\mathrm{V}, \mathrm{Cr})$ & $61.0 \pm 0.06$ & $4.6 \pm 0.20$ & $80.4 \pm 0.16$ & $3.7 \pm 0.25$ & & \\
\hline & $\mathrm{Co} 20: \mathrm{Cr} 4: \mathrm{V} 76$ & Co19.8:Cr4.4:V75.8 & $\mathrm{V}_{3} \mathrm{Co} /(\mathrm{V}, \mathrm{Cr})$ & $4.1 \pm 0.26$ & $72.1 \pm 0.20$ & $7.1 \pm 0.15$ & $82.5 \pm 0.40$ & & \\
\hline & Co19:Cr11:V70 & Co19.0:Cr11.4:V69.6 & $\mathrm{V}_{3} \mathrm{Co} /(\mathrm{V}, \mathrm{Cr})$ & $10.2 \pm 0.83$ & $67.1 \pm 0.34$ & $12.6 \pm 0.17$ & $70.0 \pm 0.22$ & & \\
\hline \multirow[t]{12}{*}{1000} & Co79:Cr4:V17 & Co78.6:Cr4.2:V17.2 & $\alpha \mathrm{Co}$ & $4.2 \pm 0.09$ & $17.2 \pm 0.08$ & & & & \\
\hline & Co70:Cr6:V24 & Co69.4:Cr6.3:V24.3 & $\alpha \mathrm{Co}$ & $6.3 \pm 0.09$ & $24.3 \pm 0.05$ & & & & \\
\hline & Co70:Cr20:V10 & Co70.5:Cr20.0:V9.5 & $\alpha \mathrm{Co}$ & $20.0 \pm 0.09$ & $9.5 \pm 0.08$ & & & & \\
\hline & Co64:Cr5:V31 & Co64.6:Cr4.9:V30.5 & $\alpha \mathrm{Co} / \sigma$ & $4.2 \pm 0.06$ & $28.2 \pm 0.17$ & $6.7 \pm 0.13$ & $34.1 \pm 0.09$ & & \\
\hline & Co60:Cr12:V28 & Co60.0:Cr11.9:V28.1 & $\alpha \mathrm{Co} / \sigma$ & $8.8 \pm 0.26$ & $24.2 \pm 0.35$ & $13.6 \pm 0.28$ & $29.0 \pm 0.32$ & & \\
\hline & Co60:Cr20:V20 & Co60.2:Cr19.9:V19.9 & $\alpha \mathrm{Co} / \sigma$ & $15.6 \pm 0.08$ & $17.7 \pm 0.19$ & $23.6 \pm 0.05$ & $21.8 \pm 0.09$ & & \\
\hline & Co56:Cr40:V4 & Co55.7:Cr40.4:V3.9 & $\alpha \mathrm{Co} / \sigma$ & $33.3 \pm 0.20$ & $3.6 \pm 0.05$ & $47.4 \pm 0.34$ & $4.3 \pm 0.12$ & & \\
\hline & Co26:Cr32:V42 & Co26.3:Cr31.5:V42.2 & $\sigma /(\mathrm{V}, \mathrm{Cr})$ & $26.3 \pm 0.13$ & $42.4 \pm 0.08$ & $45.2 \pm 0.48$ & $40.9 \pm 0.54$ & & \\
\hline & Co20:Cr4:V76 & Co19.6:Cr4.9:V75.5 & $\sigma /(\mathrm{V}, \mathrm{Cr})$ & $3.8 \pm 0.09$ & $68.1 \pm 0.13$ & $6.5 \pm 0.25$ & $77.7 \pm 0.17$ & & \\
\hline & Co20:Cr20:V60 & Co20.2:Cr20.0:V59.8 & $\sigma /(\mathrm{V}, \mathrm{Cr})$ & $13.5 \pm 0.24$ & $56.2 \pm 0.19$ & $23.9 \pm 0.17$ & $60.2 \pm 0.25$ & & \\
\hline & Co20:Cr60:V20 & $\mathrm{Co} 21.0: \mathrm{Cr} 58.8: \mathrm{V} 20.2$ & $\sigma /(\mathrm{V}, \mathrm{Cr})$ & $44.7 \pm 0.08$ & $21.8 \pm 0.13$ & $68.1 \pm 0.14$ & $18.9 \pm 0.16$ & & \\
\hline & Co20:Cr76:V4 & $\mathrm{Co} 21.0: \mathrm{Cr} 74.6: \mathrm{V} 4.4$ & $\sigma /(\mathrm{V}, \mathrm{Cr})$ & $61.3 \pm 0.15$ & $4.8 \pm 0.06$ & $81.0 \pm 0.07$ & $3.6 \pm 0.08$ & & \\
\hline \multirow[t]{8}{*}{1100} & Co64:Cr5:V31 & Co64.2:Cr5.2:V30.6 & $\alpha \mathrm{Co} / \sigma$ & $4.7 \pm 0.19$ & $28.5 \pm 0.18$ & $6.6 \pm 0.16$ & $34.6 \pm 0.19$ & & \\
\hline & Co60:Cr20:V20 & Co59.5:Cr21.4:V19.1 & $\alpha \mathrm{Co} / \sigma$ & $18.6 \pm 0.08$ & $16.3 \pm 0.30$ & $25.5 \pm 0.17$ & $20.4 \pm 0.33$ & & \\
\hline & Co56:Cr40:V4 & Co5.1:Cr40.9:V4.0 & $\alpha \mathrm{Co} / \sigma$ & $35.1 \pm 0.12$ & $3.5 \pm 0.12$ & $47.6 \pm 0.66$ & $4.3 \pm 0.09$ & & \\
\hline & Co29:Cr67:V4 & Co28.3:Cr67.6:V4.1 & $\sigma /(\mathrm{V}, \mathrm{Cr})$ & $62.3 \pm 0.19$ & $4.0 \pm 0.14$ & $75.5 \pm 0.13$ & $3.3 \pm 0.05$ & & \\
\hline & Co28:Cr53:V19 & Co28.5:Cr52.9:V18.6 & $\sigma /(\mathrm{V}, \mathrm{Cr})$ & $48.4 \pm 0.13$ & $18.6 \pm 0.07$ & $65.6 \pm 0.21$ & $16.8 \pm 0.13$ & & \\
\hline & Co26:Cr32:V42 & Co25.9:Cr32.1:V42.0 & $\sigma /(\mathrm{V}, \mathrm{Cr})$ & $26.5 \pm 0.48$ & $42.0 \pm 0.40$ & $40.9 \pm 0.50$ & $41.6 \pm 0.48$ & & \\
\hline & Co25:Cr20:V55 & Co25.2:Cr20.0:V54.8 & $\sigma /(\mathrm{V}, \mathrm{Cr})$ & $16.4 \pm 0.10$ & $53.0 \pm 0.16$ & $25.2 \pm 0.05$ & $56.3 \pm 0.09$ & & \\
\hline & Co24:Cr12:V64 & Co23.9:Cr12.3:V63.7 & $\sigma /(\mathrm{V}, \mathrm{Cr})$ & $9.9 \pm 0.03$ & $59.9 \pm 0.10$ & $15.3 \pm 0.17$ & $66.1 \pm 0.45$ & & \\
\hline \multirow[t]{8}{*}{1200} & Co60:Cr4:V36 & Co60.0:Cr4.3:V35.7 & $\alpha \mathrm{Co} / \sigma$ & $3.5 \pm 0.03$ & $29.9 \pm 0.07$ & $4.8 \pm 0.05$ & $36.0 \pm 0.16$ & & \\
\hline & Co60:Cr20:V20 & Co59.7:Cr20.0:V20.3 & $\alpha \mathrm{Co} / \sigma$ & $17.7 \pm 0.09$ & $18.4 \pm 0.14$ & $23.6 \pm 0.19$ & $22.1 \pm 0.17$ & & \\
\hline & Co56:Cr40:V4 & Co55.3:Cr40.6:V4.0 & $\alpha \mathrm{Co} / \sigma$ & $36.6 \pm 0.19$ & $3.5 \pm 0.03$ & $47.9 \pm 0.14$ & $4.2 \pm 0.14$ & & \\
\hline & Co29:Cr67:V4 & Co28.8:Cr67.2:V4.0 & $\sigma /(\mathrm{V}, \mathrm{Cr})$ & $61.3 \pm 0.13$ & $4.1 \pm 0.06$ & $70.2 \pm 0.28$ & $3.5 \pm 0.09$ & & \\
\hline & Co28:Cr53:V19 & Co27.3:Cr53.6:V19.1 & $\sigma /(\mathrm{V}, \mathrm{Cr})$ & $47.2 \pm 0.18$ & $19.5 \pm 0.26$ & $58.1 \pm 0.27$ & $18.5 \pm 0.15$ & & \\
\hline & $\mathrm{Co} 26: \mathrm{Cr} 32: \mathrm{V} 42$ & Co25.9:Cr32.1:V42.0 & $\sigma /(\mathrm{V}, \mathrm{Cr})$ & $26.3 \pm 0.14$ & $41.8 \pm 0.07$ & $35.8 \pm 0.56$ & $41.8 \pm 0.41$ & & \\
\hline & Co25:Cr20:V55 & Co24.5:Cr21.5:V53.9 & $\sigma /(\mathrm{V}, \mathrm{Cr})$ & $18.4 \pm 0.04$ & $49.9 \pm 0.03$ & $24.6 \pm 0.08$ & $54.3 \pm 0.16$ & & \\
\hline & Co24:Cr12:V64 & Co23.9:Cr1.12:V63.9 & $\sigma /(\mathrm{V}, \mathrm{Cr})$ & $9.5 \pm 0.13$ & $59.5 \pm 0.11$ & $13.2 \pm 0.08$ & $64.1 \pm 0.07$ & & \\
\hline
\end{tabular}

phase were confirmed to be the $\sigma$ phase by EPMA and XRD analysis. The two-phase microstructure $\mathrm{V}_{3} \mathrm{Co}+(\mathrm{V}, \mathrm{Cr})$ of the $\mathrm{Co} 20: \mathrm{Cr} 4: \mathrm{V} 76$ (at.\%) alloy annealed at $800{ }^{\circ} \mathrm{C}$ for 90 days is shown in Fig. 2(c), with $\mathrm{V}_{3} \mathrm{Co}$ being the dendrites. In addition, the varying contrast in the dark gray $(\mathrm{V}, \mathrm{Cr})$ phase may be caused by the coring in the alloy samples, or the different crystal orientation of the bcc $(\mathrm{V}$, $\mathrm{Cr})$ phase. Figure 2(d) shows the two-phase microstructure 
$\sigma+(\alpha \mathrm{Co})$ in the Co56:Cr40:V4 (at.\%) alloy annealed at $1000{ }^{\circ} \mathrm{C}$ for 60 days. Figure $2(\mathrm{e})$ shows the two-phase microstructure $\sigma+\mathrm{V}_{3}$ Co of the Co64:Cr5:V31 (at.\%) alloy annealed at $1000{ }^{\circ} \mathrm{C}$ for 60 days, where the dendrites were $\mathrm{VCo}_{3}$. In the Co29:Cr67:V4 (at.\%) alloy annealed at $1100{ }^{\circ} \mathrm{C}$ for 45 days, $\sigma$ and $(\mathrm{V}, \mathrm{Cr})$ were identified, as shown in Fig. 2(f), and XRD presented in Fig. 3(b) confirmed these phases.

\subsection{Isothermal Sections}

The analyzed compositions of the Co-Cr-V ternary system at $800,1000,1100$ and $1200{ }^{\circ} \mathrm{C}$ determined by EPMA are listed in Table 2. Using these experimental data, the isothermal sections at $800,1000,1100$ and $1200{ }^{\circ} \mathrm{C}$ were constructed in Fig. 4-7. In all cases, the overall

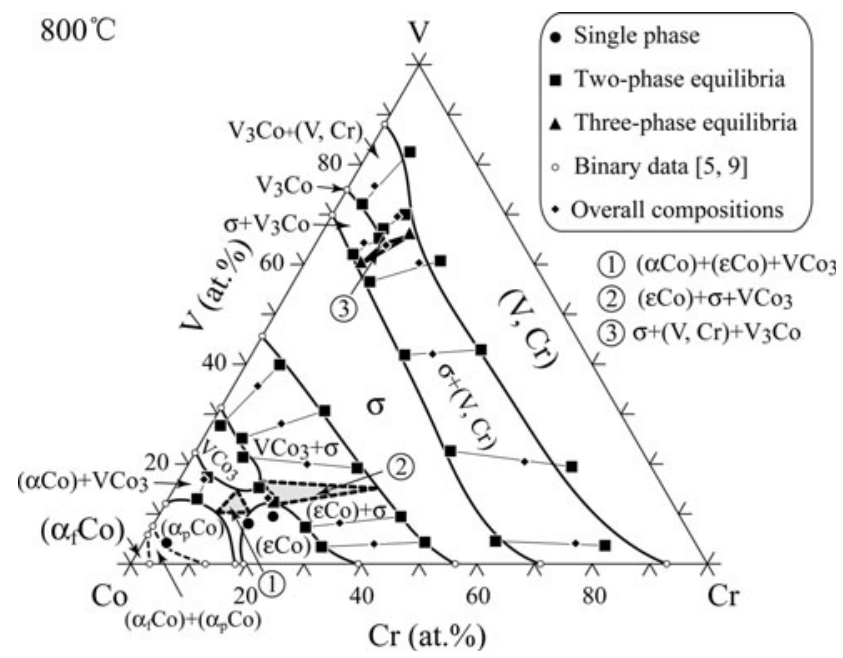

Fig. 4 Experimentally determined isothermal section of the $\mathrm{Co}-\mathrm{Cr}-\mathrm{V}$ system at $800{ }^{\circ} \mathrm{C}$

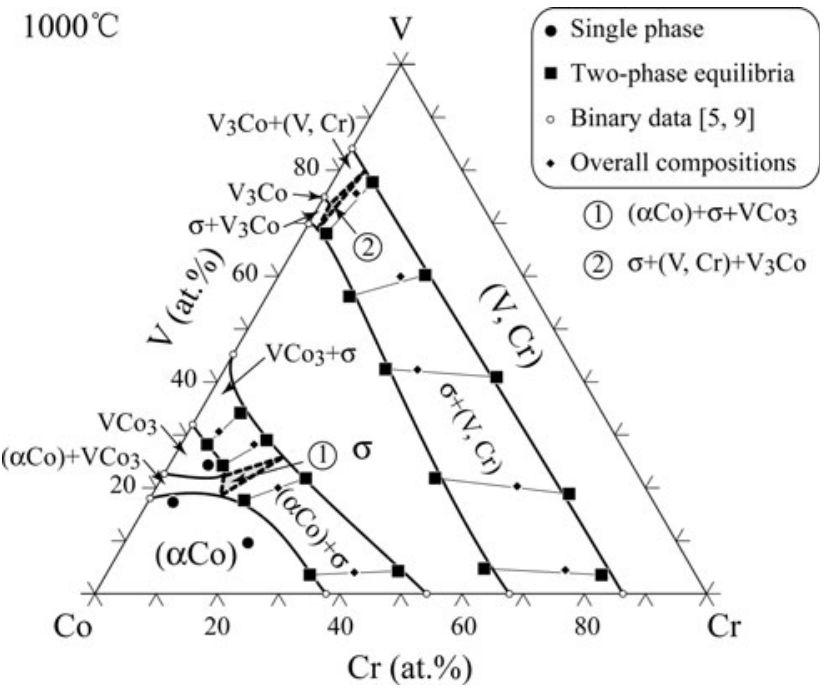

Fig. 5 Experimentally determined isothermal section of the Co-Cr-V system at $1000{ }^{\circ} \mathrm{C}$ composition was on the tie line in the two phase samples. At $800{ }^{\circ} \mathrm{C}$, Fig. 4 , there are four single-phase regions: $(\alpha \mathrm{Co})$, $(\varepsilon \mathrm{Co}), \mathrm{VCo}_{3},(\mathrm{~V}, \mathrm{Cr})$, and $\sigma$, and one determined threephase region $\sigma+(\mathrm{V}, \mathrm{Cr})+\mathrm{V}_{3} \mathrm{Co}$. Two three-phase equilibria: $(\alpha \mathrm{Co})+(\varepsilon \mathrm{Co})+\mathrm{VCo}_{3},(\varepsilon \mathrm{Co})+\mathrm{VCo}_{3}+\sigma$ and the phase separation of $\left(\alpha_{\mathrm{f}} \mathrm{Co}\right)+\left(\alpha_{\mathrm{p}} \mathrm{Co}\right)$, shown as dashed lines were inferred, and were not found in the current samples. The $\sigma$ and $(\mathrm{V}, \mathrm{Cr})$ phases formed continuous solid solutions from the $\mathrm{Co}-\mathrm{Cr}$ side to $\mathrm{Co}-\mathrm{V}$ side, and $\mathrm{V}_{3} \mathrm{Co}$ behaved as a line compound.

The isothermal section at $1000{ }^{\circ} \mathrm{C}$ is shown in Fig. 5, where four two-phase regions $(\alpha \mathrm{Co})+\mathrm{VCo}_{3},(\alpha \mathrm{Co})+\sigma$,

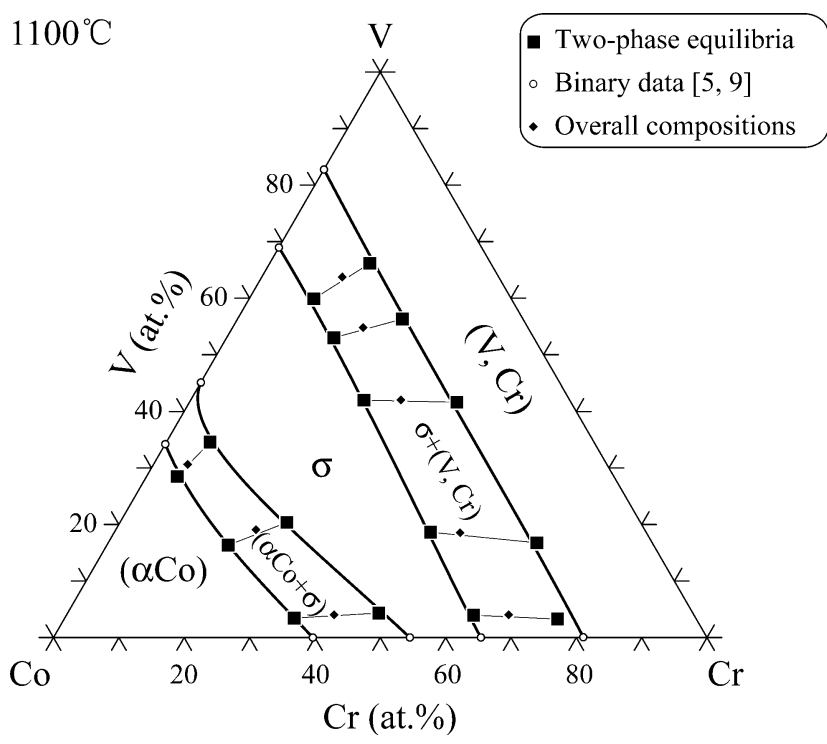

Fig. 6 Experimentally determined isothermal section of the Co-Cr-V system at $1100{ }^{\circ} \mathrm{C}$

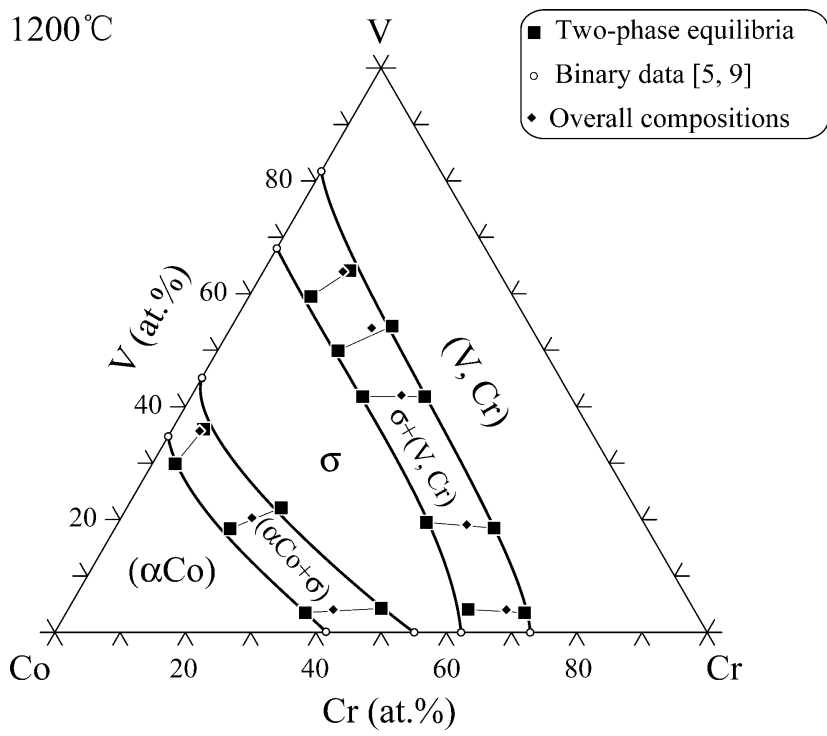

Fig. 7 Experimentally determined isothermal section of the Co-Cr-V system at $1200{ }^{\circ} \mathrm{C}$ 
$\mathrm{VCo}_{3}+\sigma$, and $\sigma+(\mathrm{V}, \mathrm{Cr})$ were identified. The $\mathrm{VCo}_{3}$ and $\mathrm{V}_{3} \mathrm{Co}$ phases at $1000{ }^{\circ} \mathrm{C}$ (Fig. 5), disappeared at $1100{ }^{\circ} \mathrm{C}$ (Fig. 6), where only three single-phase regions $(\alpha \mathrm{Co}),(\mathrm{V}$, $\mathrm{Cr})$, and $\sigma$ and two two-phase regions $(\alpha \mathrm{Co})+\sigma$, and $\sigma+(\mathrm{V}, \mathrm{Cr})$ appeared. The phase relationship shown in the isothermal section at $1200{ }^{\circ} \mathrm{C}$ (Fig. 7) is similar to that at $1100{ }^{\circ} \mathrm{C}$, although the solubilities of phases were slightly different, due to the different temperatures. It should be noted that not all phase boundaries were drawn through the data points in Fig. 4-7, especially for Fig. 4. This is likely to be because the phases had not attached equilibrium, or that the boundaries were actually more curved than indicated on the figures.

\section{Conclusions}

Four isothermal sections of the Co-Cr- $\mathrm{V}$ ternary system at $800,1000,1100$ and $1200{ }^{\circ} \mathrm{C}$ were experimentally determined. No ternary compound was found in this system. The $\sigma$ and $(\mathrm{V}, \mathrm{Cr})$ phases formed continuous solid solutions from the $\mathrm{Co}-\mathrm{Cr}$ side to $\mathrm{Co}-\mathrm{V}$ side at all temperatures examined.

\section{Acknowledgments}

This work was supported by the National Natural Science Foundation of China (Grant Nos. 51031003 and 50971109 ) and the Ministry of Science and Technology of China (Grant Nos. 2009DFA52170 and 2009AA03Z101). The support from Fujian Provincial Department of Science \& Technology (Grant No. 2009I0024), Xiamen City Department of Science \& Technology (Grant No. 3502Z20093001), and Aviation Science Fund (Grant No. 2009ZF68010) are also acknowledged. In addition, one of the authors Mr. Yan Yu would like to thank the support from the Fundamental Research Funds for the Central Universities (Grant No. 201112G013).

\section{References}

1. M.L. Plumer, J. Van Ek, and D. Weller, The Physics of UltraHigh-Density Magnetic Recording, Springer, New York, 2001

2. S. Khizroev and D. Litvinov, Perpendicular Magnetic Recording, Kluwer Academic, Boston, 2004

3. C.D. Mee and E.D. Daniel, Magnetic Recording Technology, McGraw-Hill, New York, 1996

4. E.D. Daniel, C.D. Mee, and M.H. Clark, Magnetic Recording: The First 100 Years, IEEE Press, New York, 1999

5. H. Okamoto, Co-V (Cobalt-Vanadium), J. Phase Equilib. Diffus., 2006, 27(2), p 198

6. V.N. Kuznetsov, G.P. Zhmurko, Zh.N. Toibayev, K.B. Kalmykov, L.M. Aziyeva, and L.S. Guzei, Experimental Research and Thermodynamic Simulation of Phase Equilibria in Co-Cr-V System, Mosc. Univ. Chem. Bull., 2001, 42, p 121124 , in Russian

7. A. Kusoffsky and B. Jansson, A Thermodynamic Evaluation of the Co-Cr and the C-Co-Cr Systems, CALPHAD, 1997, 21(3), p 321-333

8. K. Ishida and T. Nishizawa, The Co-Cr (Cobalt-Chromium) System, J. Phase Equilib., 1990, 11(4), p 357-370

9. K. Oikawa, G.W. Qin, T. Ikeshoji, R. Kainuma, and K. Ishida, Direct Evidence of Magnetically Induced Phase Separation in the FCC Phase and Thermodynamic Calculations of Phase Equilibria of the Co-Cr System, Acta Mater., 2002, 50(9), p 2223-2232

10. H. Okamoto, Co-V (Cobalt-Vanadium), J. Phase Equilib. Diffus., 2007, 28(3), p 314

11. S.G. Huang, L. Li, O. Van der Biest, and J. Vleugels, Thermodynamic Assessment of the Co-V and Co-V-C System, J. Alloys Compd., 2004, 385(1-2), p 114-118

12. J. Smith, The Co-V (Cobalt-Vanadium) System, J. Phase Equilib., 1991, 12(3), p 324-331

13. J.F. Smith, Phase Diagrams of Binary Vanadium Alloys, ASM International, Materials Park, OH, 1989 